\title{
Lack of proliferation of circulating white blood cells in patients with syphilis before and after a Jarisch-Herxheimer reaction
}

\author{
MAIJA HORSMANHEIMO \\ From the Department of Dermatology, University Central Hospital, Helsinki, Finland
}

SUMMARY The occurrence of lymphoblasts in peripheral blood, measured by incorporating tritiated thymidine $([3 \mathrm{H}] \mathrm{dThd})$, was studied before, during, and after a Jarisch-Herxheimer reaction in patients with early syphilis. No difference in $[3 \mathrm{H}] \mathrm{dThd}$ incorporation into peripheral white blood cells was found between five patients with syphilis and 19 healthy controls, whereas in 20 cord blood samples $[3 \mathrm{H}] \mathrm{dTh}$ incorporation was significantly increased.

\section{Introduction}

The pathogenesis of the Jarisch-Herxheimer reaction (JHR) remains obscure. It has been suggested that the JHR is caused by the reaction of treponemal breakdown substances with sensitised syphilitic tissue (Sheldon and Heyman, 1949) or by the release of leucocyte endogenous pyrogen or other plasma kinins by treponemal substances (Schofield et al., 1968). Although the release of histamine is not an important factor in the symptoms of JHR (Heyman et al., 1952; Zachariae and Nielsen, 1974), it has been suggested that cell-mediated immune mechanisms play a role, and many reports have documented the importance of cell-mediated immune reactions in syphilis (Festenstein, et al., 1967; Bădănoiu et al., 1969; Levene et al., 1969, 1971; Fulford and Brostoff, 1972; Wright and Grimble, 1974; Musher et al., 1974, 1975; From et al., 1976).

Small numbers of immature, proliferating white blood cells can be found in the peripheral blood of healthy subjects. Increased numbers of proliferating mononuclear leucocytes are seen in the blood in a wide variety of infections (Lalla, 1974). In addition, a proliferative response of circulating blood cells has been reported after immunisation, after virus vaccination, and after clinically positive provocation tests to the drugs which previously had caused rashes in the same patients (Lalla, 1974). The size of this response has been found to be related to the strength of the antigenic stimulus.

Address for reprints: Maija Horsmanheimo, MD, Department of Dermatology, University Central Hospital, Snellmaninkatu 14, SF-00170 Helsinki 17, Finland

Received for publication 3 January 1978
The present study was undertaken to investigate whether proliferating white blood cells could be found in the peripheral blood of patients with syphilis.

\section{Materials and methods}

Three men (aged 18, 23, and 47 years) and two women (aged 21 and 22 years) from the Department of Dermatology, University Central Hospital, Helsinki, were studied. They were all in hospital and suffering from early syphilis, two in the primary stage and three in the secondary stage. All gave positive results by standard serological tests for syphilis. In addition, treponemes (Treponema pallidum) were found in the primary chancres of the two patients with primary stage and in one of the patients with secondary stage syphilis.

All patients received 600000 units of sodium penicillin in the morning, and features of the JHR were observed each hour until the fever had subsided. The patients did not receive any other drug. The highest temperatures during the JHR in these patients were $39 \cdot 5,38 \cdot 6,38,37 \cdot 8$, and $37 \cdot 3^{\circ} \mathrm{C}$. A macular rash appeared in one of the patients during the JHR, two patients claimed headache, and one had pain in his enlarged inguinal lymph nodes. After the JHR, all patients continued to be treated with 600000 units a day of procaine penicillin.

The control series comprised 19 age-matched healthy volunteers (employees of the University Central Hospital). As a positive control, 20 samples of cord blood were also studied. Cord blood was obtained from the Department of Obstetrics and Gynaecology after normal deliveries. 
Two millilitres of peripheral venous blood or cord blood was withdrawn into a prewarmed $\left(37^{\circ} \mathrm{C}\right)$ syringe containing $0.5 \mathrm{ml}$ of $6 \%$ dextran, 50 iu heparin, and $2.5 \mu \mathrm{Ci}$ tritiated thymidine ([3H]dThd, specific activity $6.7 \mathrm{Ci} / \mathrm{mmol}$ ) (New England Nuclear Corporation). After incubation for an hour at $37^{\circ} \mathrm{C}$ the buffy coats were collected. The cells were counted in a haemocytometer. Cell preparations were made with a cytocentrifuge (Shandon Scientific Co. Ltd, London) and were stained with MayGrunwald-Giemsa (MGG) stain. Two aliquots of $0.2 \mathrm{ml}$ were immediately chilled and used for scintillation counting (Packard, Model No. 3375). The results for tritiated thymidine incorporation into DNA are given as counts per minute per $10^{6}$ white blood cells.

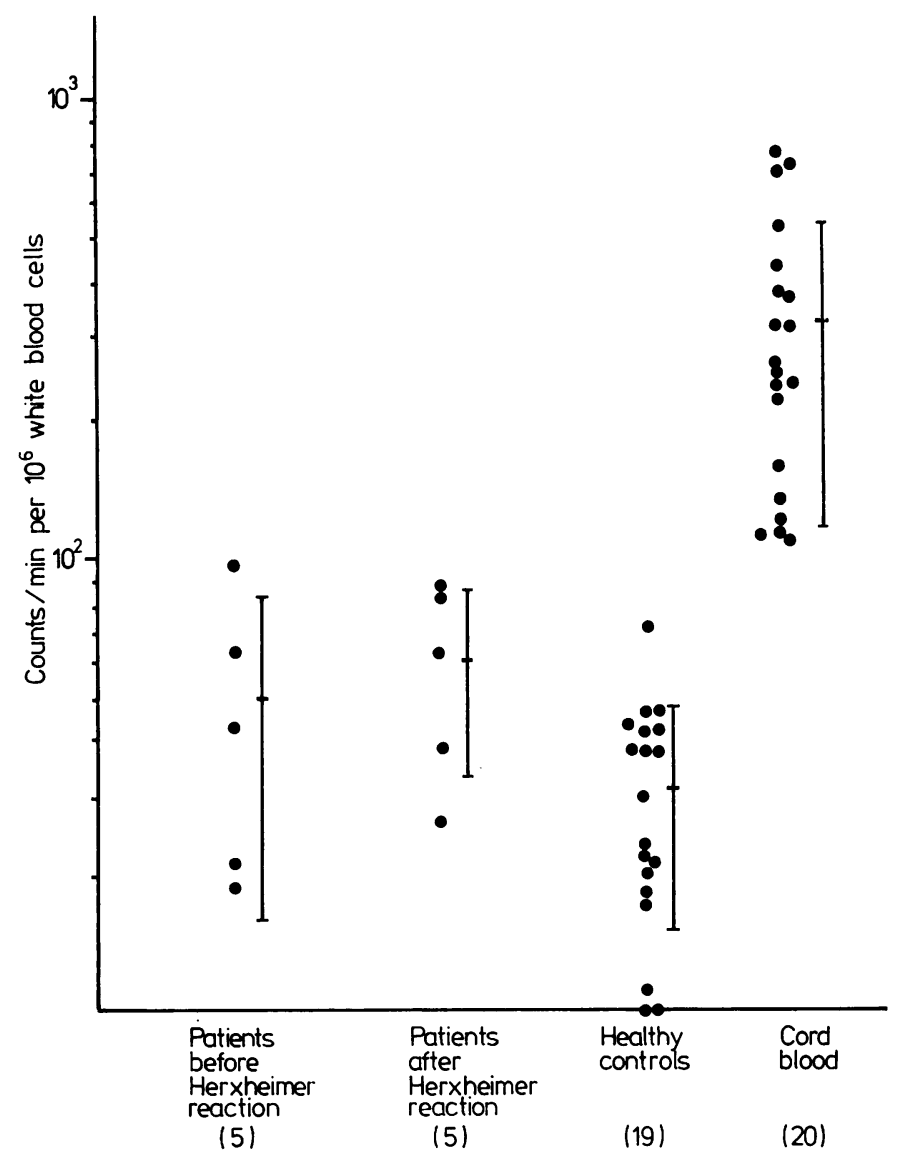

Figure [3H]dThd incorporation into white blood cells in patients with early syphilis before and after Jarisch-Herxheimer reaction, in healthy controls, and in cord blood samples.

\section{Results}

Before the study began, the optimal incubation time of the cells with [3H]dThd was studied. Incubation for one hour at $37^{\circ} \mathrm{C}$ was found to be a reliable labelling time in controls and cord blood. Longer incubation did not significantly increase the incorporation of isotope into the cells. As in previous studies (Lalla, 1974), blast responses were studied on the fifth day. [3H]dThd incorporation before the JHR was $49 \pm 33$ (mean \pm SD) in patients with syphilis, $31 \pm 16$ in 19 controls, and $323 \pm 208$ in 20 cord blood samples (Figure). After the JHR, [3H]dThd incorporation was $59 \pm 26$ in the patients with syphilis, which did not differ significantly from the values before JHR or from those of the controls. 
[3H]dThd incorporation in cord blood was significantly higher than in adults $(\mathrm{P}<0.001$ by Student's $t$ test). In addition, in one of the patients, incorporation was measured after eight hours, when the fever had reached its maximum, and in two patients after one day of the penicillin dose. In one patient incorporation was measured after two days, in two patients after three days, and in one after four days; the values did not differ significantly from those on the fifth day.

\section{Discussion}

The number of proliferating cells in the peripheral blood increases in a variety of infections, after immunisation, and during the course of some other diseases in which immunological mechanisms play a central role (Lalla, 1974). Parallel in vivo and in vitro studies with bone marrow indicate that the in vitro results within the first hour of incubation with $[3 \mathrm{H}] \mathrm{dTh}$ are identical with those obtained in vivo, when bone marrow cells are removed one hour after injection of the label (Bond et al., 1959; Rubini et al., 1960). Therefore, incorporation within the first hour in vitro seems to reflect the in vivo capacity of the cells for DNA synthesis. The advantage of the present method is that the separation of buffy coat cells and incorporation of $[3 \mathrm{H}] \mathrm{dTh}$ takes place simultaneously and immediately after the withdrawal of the peripheral blood cells.

The timing of the lymphoblast response to antigenic stimulation has already been studied in healthy volunteers after immunisation with bacterial vaccines and after stimulation with four antigens combined (Gump and Fekety, 1967; Crowther et al., 1969). The peak proliferative response was between five and seven days later. In cutaneous hypersensitivity reactions after clinically positive provocation test with sulphonamides and some other drugs, the maximum blood lymphoblast proliferation in vivo was observed five days after the test (Lalia and Virolainen, 1974). Five days were also required for the optimal lymphocyte transformation response to antigens in vitro (Horsmanheimo and Virolianen, 1974). Thus, this in vivo lymphocyte transformation is probably analogous to the antigen-induced transformation of specific lymphocytes in vitro (Crowther et al., 1969; Virolainen et al., 1974).

In healthy adults, a very low level of $[3 \mathrm{H}] \mathrm{dThd}$ incorporation was found in the present study, in accord with previous studies (Lalla, 1974). In addition, large numbers of DNA-synthesising cells were found in cord blood samples, as has also been reported previously (Lalla, 1974). DNA-synthesising cells in cord blood have been shown to be pre- dominantly labelled myeloid or erythroid cells, and only small numbers of lymphoblasts have been found (Lalla, 1975). The increase in the number of lymphoblasts takes place between four and seven days after birth (Lalla, 1975) and probably represents a response of the lymphoid system to the enormous number of new antigens met by the organism.

The lack of $[3 \mathrm{H}] \mathrm{dTh}$ incorporation by peripheral blood cells of patients with early syphilis indicates that stimulation of peripheral blood lymphocytes by $T$. pallidum antigen occurs neither in early syphilis nor after JHR, in which large amounts of treponemal breakdown substances are released. The results with this new method support the findings of some previous studies dealing with cell-mediated immunity in the early stage of syphilis. Musher et al. (1974) found that cell-mediated hypersensitivity skin reaction to treponemal antigens was negative in the primary stage of syphilis, in contrast to the latent stage in which it became positive. Furthermore, inhibition of leucocyte migration in the presence of proteins from Reiter treponemes has been demonstrated in the late latent stage of the disease, whereas leucocyte migration is normal or even enhanced in patients with primary syphilis (Fulford and Brostoff, 1972). In the lymphocyte transformation test, the treponemal antigen and Reiter protein-induced blast response have been found to be lowest in early primary syphilis (Bădănoiu et al., 1969; Fulford and Brostoff, 1972). In addition, Levene et al. (1969) found a significant reduction in lymphocyte transformation in the presence of phytohaemagglutinin (PHA) in patients with primary and secondary syphilis, and plasma from patients with secondary syphilis suppressed transformation of normal lymphocytes. Since the in vivo blast response in peripheral blood may be related to the in vitro transformation of sensitised lymphocytes in response to the specific antigen, it is suggested that the same mechanisms resulting in the inhibition of lymphocyte transformation in vitro in early syphilis may be responsible for the lack of (3H)dThd incorporation by peripheral blood cells from patients with syphilis demonstrated in this study. This reduction of lymphocyte reactivity could be caused by an excess of treponemal antigen, antigen-antibody immune complexes, a circulating antilymphocyte antibody, or by some othet inhibitory factor(s).

The lack of $[3 \mathrm{H}] \mathrm{dT}$ Thd incorporation by peripheral blood cells during and after the Jarisch-Herxheimer reaction does not support the possibility that this reaction is the result of an immunisation state induced by treponemal antigen. However, the existence of inhibitory mechanisms responsible for the lack of blast responses cannot be ruled out. 
Assistance by Charles L. Smith in preparing the manuscript is gratefully acknowledged.

\section{References}

Bădănoiu, A., Gavrilesco, M., Nicolau, G., and Circiumaresco, T. (1969). Lymphoblastogenése immunoallergique et antigène tréponémique in vitro dans la syphilis. Archives roumaines de pathologie expérimentale et de microbiologie, 28, 419-427.

Bond, V. P., Fliedner, T. M., Cronkite, E. P., Rubini, J. R., Brecher, G., and Schork, P. K. (1959). Proliferative potentials of bone marrow and blood cells studied in vitro uptake of $\mathbf{H}^{3}$-thymidine. Acta haematologica, 21, 1-15.

Crowther, D., Fairley, G. H., and Sewell, R. L. (1969). Lymphoid cellular responses in the blood after immunization in man. Journal of Experimental Medicine, 129, 849-869.

Festenstein, H., Abrahams, C., and Bokkenheuser, V. (1967). Runting syndrome in neonatal rabbits infected with Treponema pallidum. Clinical and Experimental Immunology, 2, 311-320.

From, E., Thestrup-Pedersen, K., and Thulin, H. (1976). Reactivity of lymphocytes from patients with syphilis towards $T$. pallidum antigen in the leucocyte migration and lymphocyte transformation tests. British Journal of Venereal Diseases, 52, 224-229.

Fulford, K. W. M., and Brostoff, J. (1972). Leucocyte migration and cell-mediated immunity in syphilis. British Journal of Venereal Diseases, 48, 483-488.

Gump, D. W., and Fekety, F. R. (1967). The relationship of infection and DNA-synthesizing cells in human blood. Journal of Laboratory and Clinical Medicine, 69, 428-437.

Heyman, A., Sheldon, W. H., and Evans, L. D. (1952). Pathogenesis of the Jarisch-Herxheimer reaction: A review of clinical and experimental observations. British Journal of Venereal Diseases, 28, 50-60.

Horsmanheimo, M., and Virolainen, M. (1974). Enhancement of tuberculin-induced lymphocyte transformation by precultivated macrophages from patients with sarcoidosis. Scandinavian Journal of Immunology, 3, 21-27.
Lalla, M. (1974). Proliferation of circulating human white cells in health and in non-neoplastic disorders. Thesis (ISBN 951-990449-2), Helsinki.

Lalla, M. (1975). Proliferation of blood leucocytes in the neonatal period. Acta haematologica, 53, 129-137.

Lalla, M., and Virolainen, M. (1974). Blood lymphoblast proliferation in vivo in cutaneous drug hypersensitivity reactions. International Archives of Allergy and Applied Immunology, 46, 289-299.

Levene, G. M., Turk, J. L., Wright, D. J. M., and Grimble, A. G. S. (1969). Reduced lymphocyte transformation due to a plasma factor in patients with active syphilis. Lancet, 2, 246-247.

Levene, G. M., Wright, D. J. M., and Turk, J. L. (1971). Cellmediated immunity and lymphocyte transformation in syphilis. Proceedings of the Royal Society of Medicine, 64, 426-428.

Musher, D. M., Schell, R. F., Jones, R. F., and Jones, A. M. (1975). Lymphocyte transformation in syphilis: an in vivo correlate of immune suppression in vivo? Infection and Immunity, 11, 1261-1264.

Musher, D. M., Schell, R. F., and Knox, J. M. (1974). In vitro lymphocyte response to Treponema refrigens in human syphilis. Infection and Immunity, 9, 654-657.

Rubini, J. R., Cronkite, E. P., Bond, V. P., and Fliedner, T. M. (1960). The metabolism and fate of tritiated thymidine in man. Journal of Clinical Investigation, 39, 909-918.

Schofield, T. P. C., Talbot, J. M., Bryceson, A. D. M., and Parry, E. H. O. (1968). Leucopenia and fever in the Jarisch-Herxheimer reaction of louse-borne relapsing fever. Lancet, 1, 58-62.

Sheldon, W. H., and Heyman, A. (1949). Morphologic changes in syphilitic lesions during Jarisch-Herxheimer reaction. American Journal of Syphilis, Gonorrhea, and Venereal Diseases, 33, 213-224.

Virolainen, M., Lalla, M., Pasternack, A., Wasastjerna, C., and Häyry, P. (1974). DNA-synthesizing myeloid and lymphoid cells in the blood of haemodialysis patients and kidney graft recipients. Scandinavian Journal of Haematology, 12, 391-400.

Wright, D. J. M., and Grimble, A. S. (1974). Why is the infectious stage of syphilis prolonged? British Journal of Venereal Diseases, 50, 45-49.

Zachariae, H., and Nielsen, E. (1974). Plasma kinins and the JarischHerxheimer reaction. Acta dermato-venereologica, 54, 401-402. 